\title{
Speed Estimation of Stator Field Orientation Control Induction Motor Drive Based on the Particle Swarm Optimization Algorithm
}

\author{
Yung-Chang Luo, ${ }^{*}$ Chen-Lung Tsai, and Ying-Piao Kuo \\ Department of Electrical Engineering, National Chin-Yi University of Technology, \\ No. 57, Sec 2, Zhongshan Rd., Taiping Dist., Taichung 41170, Taiwan (ROC)
}

(Received October 27, 2017; accepted January 4, 2018)

Keywords: speed estimation, flux observer, current sensor, particle swarm optimization (PSO) algorithm, stator field orientation control (SFOC) induction motor (IM) drive

In this study, flux-observer-based speed estimation was used to achieve stator field orientation control (SFOC) of an induction motor (IM) drive utilizing both stator current and stator flux, and the stator current was obtained from an IM by utilizing Hall effect current sensors. The speed estimation scheme was designed in accordance with the Lyapunov stability theory, and the flux observer gain matrix was acquired by the application of a modified particle swarm optimization (PSO) algorithm. The MATLAB/Simulink toolbox was used for simulation, and all the control algorithms were realized using a 32-bit RX62T micro controller to generate pulse width modulation (PWM) signals to the power stage, to drive the motor, and to validate this approach. Both simulation and experimental results confirmed the effectiveness of the proposed system.

\section{Introduction}

Induction motor (IM) drives utilizing the field orientation control (FOC) method can achieve an excellent torque-to-current ratio. According to the FOC theory, by utilizing the appropriate coordinate transformation, a time-variant, nonlinear coupled mathematical model of an IM, in which flux and torque are both orthogonal and independent, ${ }^{(1)}$ can be as efficient as a DC motor. The FOC method employed in an IM drive may be classified as stator, rotor, or air-gap types. In stator FOC, the stator current and stator flux are the state variables. In rotor FOC, the stator current and rotor flux are the variables. In air-gap FOC, the stator current and air-gap flux are the variables. The stator current for conventional FOC IM drives is obtained from an IM by utilizing Hall effect current sensors. However, for the implementation of FOC IM drives, a motor shaft position sensor such as an encoder is needed to detect rotor speed. This makes the system less reliable and unsuitable for a hostile environment. Hence, the development of a speed estimation method for an FOC IM drive to replace that used for a conventional FOC is required. Several speed estimation methods for FOC IM drives have been established: speed determination by a flux estimator, ${ }^{(2-4)}$ speed estimation by a model reference adaptive system, ${ }^{(5-7)}$ a speed adjustment approach using an extended Kalman filter, ${ }^{(8,9)}$ and the use of

*Corresponding author: e-mail: luoyc@ncut.edu.tw http://dx.doi.org/10.18494/SAM.2018.1788 
fuzzy logic or a neural network to determine rotor speed. ${ }^{(10-12)}$

In this study, the flux observer approach is proposed. This method has the advantage of simple structure and easy implementation. An exact observer gain matrix is necessary for the implementation of the speed estimation of stator field orientation control (SFOC) IM drive with flux observer. Gain matrix parameter adjustment in conventional flux-observer-based speed estimation for these drives is carried out by trial and error, or is based on past experiences, and is a very tedious process. Use of the particle swarm optimization (PSO) algorithm is one way to achieve optimum control. It allows rapid convergence, has low operational cost, and is suitable for a range of different conditions. ${ }^{(13)}$ Hence, the PSO algorithm was used to adjust the gain matrix parameters of the proposed flux observer in this study.

This paper has four sections. In Sect. 1, research motivation, background, and a literature review of speed estimation methods for FOC IM drives are introduced. The decoupled SFOC IM drive system used in this study is covered in Sect. 2. The stator flux observer design based on the Lyapunov stability theory and the use of the PSO algorithm to acquire the observer gain matrix parameters are described in Sect. 3. The simulation and experiment are discussed in Sect. 4.

\section{SFOC IM Drive}

The vector state equations of an IM are expressed using the stator current and stator flux at the synchronous reference coordinate frame ${ }^{(14)}$ given by

$$
\begin{gathered}
p \vec{i}_{s}^{e}=-\left(\frac{R_{s}}{L_{\sigma}}+\frac{1}{\sigma \tau_{r}}+j \omega_{s l}\right) \vec{i}_{s}^{e}+\frac{1}{L_{\sigma}}\left(\frac{1}{\tau_{r}}-j \omega_{r}\right) \vec{\lambda}_{s}^{e}+\frac{1}{L_{\sigma}} \vec{v}_{s}^{e}, \\
p \vec{\lambda}_{s}^{e}=\vec{v}_{s}^{e}-R_{s} \vec{i}_{s}^{e}-j \omega_{e} \vec{\lambda}_{s}^{e},
\end{gathered}
$$

where $j$ is the imaginary part, $\vec{v}_{s}^{e}=v_{d s}^{e}+j v_{q s}^{e}$ and $\vec{i}_{s}^{e}=i_{d s}^{e}+j i_{q s}^{e}$ are the stator voltage and current vectors, respectively, $\vec{\lambda}_{s}^{e}=\lambda_{d s}^{e}+j \lambda_{q s}^{e}$ is the stator flux vector, $R_{s}$ and $R_{r}$ are the stator and rotor resistances, respectively, $L_{s}$ and $L_{r}$ are the stator and rotor inductances, respectively, $L_{m}$ is the mutual inductance between stator and rotor, $\tau_{r}=L_{r} / R_{r}$ is the rotor time constant, $\sigma=1-\left(L_{m}^{2} / L_{s} L_{r}\right)$ is the leakage inductance coefficient, $L_{\sigma}=\sigma L_{s}$ is the stator leakage inductance, $\omega_{e}$ is speed of the synchronous reference coordinate frame, $\omega_{r}$ is the electric speed of the rotor, $\omega_{s l}=\omega_{e}-\omega_{r}$ is the slip speed, and $p=d / d t$ is the differential operator. The developed electromagnetic torque of an IM is obtained as

$$
T_{e}=\frac{3 P}{4}\left(i_{q s}^{e} \lambda_{d s}^{e}-i_{d s}^{e} \lambda_{q s}^{e}\right)
$$

where $P$ is the number of motor poles. The mechanical equation of the motor is

$$
J_{m} p \omega_{r m}+B_{m} \omega_{r m}=T_{e}-T_{L},
$$

where $J_{m}$ is the inertia of the motor, $B_{m}$ is the viscous friction coefficient, $T_{L}$ is the load torque, 
and $\omega_{r m}$ is the mechanical speed of the motor shaft. The speed of the motor shaft can also be expressed as

$$
\omega_{r m}=\frac{2}{P} \omega_{r}
$$

The adaptation of Eqs. (1) and (2) allows a two-axis state matrix equation of an IM to be acquired as

$$
p\left[\begin{array}{c}
i_{d s}^{e} \\
i_{q s}^{e} \\
\lambda_{d s}^{e} \\
\lambda_{q s}^{e}
\end{array}\right]=\left[\begin{array}{cccc}
-\left(\frac{R_{s}}{L_{\sigma}}+\frac{1}{\sigma \tau_{r}}\right) & \omega_{s l} & \frac{1}{L_{\sigma} \tau_{r}} & \frac{1}{L_{\sigma}} \omega_{r} \\
-\omega_{s l} & -\left(\frac{R_{s}}{L_{\sigma}}+\frac{1}{\sigma \tau_{r}}\right) & -\frac{1}{L_{\sigma}} \omega_{r} & \frac{1}{L_{\sigma} \tau_{r}} \\
-R_{s} & 0 & 0 & \omega_{e} \\
0 & -R_{s} & -\omega_{e} & 0
\end{array}\right]\left[\begin{array}{c}
i_{d s}^{e} \\
i_{q s}^{e} \\
\lambda_{d s}^{e} \\
\lambda_{q s}^{e}
\end{array}\right]+\left[\begin{array}{cc}
\frac{1}{L_{\sigma}} & 0 \\
0 & \frac{1}{L_{\sigma}} \\
1 & 0 \\
0 & 1
\end{array}\right]\left[\begin{array}{c}
v_{d s}^{e} \\
v_{q s}^{e}
\end{array}\right]
$$

The simulation of an IM model was designed using Eqs. (3)-(6).

With the SFOC condition set at $\lambda_{q s}^{e}=0$ in Eq. (1), the slip speed and the $d$-axis stator flux are derived as

$$
\begin{gathered}
\omega_{s l}=\frac{\left(1+\sigma \tau_{r} s\right) L_{s} i_{q s}^{e}}{\tau_{r}\left(\lambda_{d s}^{e}-\sigma L_{s} i_{d s}^{e}\right)}, \\
\lambda_{d s}^{e}=\frac{\left(1+\sigma \tau_{r} s\right) L_{s}}{\left(1+\tau_{r} s\right)} i_{d s}^{e}-\frac{\sigma \tau_{r} \omega_{s l} L_{s}}{\left(1+\tau_{r} s\right)} i_{q s}^{e},
\end{gathered}
$$

where $s$ is the Laplace operator.

Examination of Eq. (8) reveals that $q$-axis stator current coupling exists in the second term of the right side, defining the feedforward compensation as

$$
i_{d q}^{e}=\frac{\sigma \tau_{r} \omega_{s l} L_{s}}{\left(1+\tau_{r} s\right)} i_{q s}^{e}
$$

The linear control between the $d$-axis stator flux and the $d$-axis stator current can then be obtained as

$$
\lambda_{d s}^{e}=\frac{\left(1+\sigma \tau_{r} s\right) L_{s}}{\left(1+\tau_{r} s\right)} i_{d s}^{e}
$$

The electromagnetic torque of an IM developed under an SFOC condition is acquired as

$$
T_{e}=\frac{3 P}{4} i_{q s}^{e} \lambda_{d s}^{e}
$$

Both the $d$-axis stator flux and the $q$-axis stator current are orthogonal in Eq. (11), and the maximum toque-to-current ratio can be attained under an SFOC condition. 
Also, set $\lambda_{q s}^{e}=0$ in Eq. (2), and the $d$-axis and $q$-axis stator voltage equations under an SFOC condition are given by

$$
\begin{aligned}
& R_{s} i_{d s}^{e}+p \lambda_{d s}^{e}=v_{d s}^{e}, \\
& R_{s} i_{q s}^{e}+\omega_{e} \lambda_{d s}^{e}=v_{q s}^{e} .
\end{aligned}
$$

Examination of Eq. (12) reveals a linear control of the $d$-axis stator current loop, and examination of Eq. (13) shows that $d$-axis stator voltage coupling exists in the second term of the left side. This permits the definition of feed-forward compensation as $\omega_{e} \lambda_{d s}^{e}$; the linear control of the $q$-axis stator current loop can also be obtained.

The voltage command of the $d$-axis and $q$-axis stator current loops is acquired as

$$
\begin{gathered}
v_{d s}^{e^{*}}=v_{d s}^{e^{\prime}}, \\
v_{q s}^{e^{*}}=v_{q s}^{e^{\prime}}+\omega_{e} \lambda_{d s}^{e},
\end{gathered}
$$

where $v_{d s}^{e^{\prime}}$ and $v_{q s}^{e^{\prime}}$ are the outputs of the $d$-axis and $q$-axis stator current controllers, respectively.

\section{Stator Flux Observer Design}

In the two-axis stationary reference coordinate frame $\left(\omega_{e}=0\right)$, according to Eqs. (1) and (2), the stator flux observer can be defined as

$$
p\left[\begin{array}{c}
\hat{\vec{i}}_{s}^{s} \\
\hat{\vec{\lambda}}_{s}^{s}
\end{array}\right]=\left[\begin{array}{cc}
-\left(\frac{R_{s}}{L_{\sigma}}+\frac{1}{\sigma \tau_{r}}-j \hat{\omega}_{r}\right) & \frac{1}{L_{\sigma}}\left(\frac{1}{\tau_{r}}-j \hat{\omega}_{r}\right) \\
-R_{s} & 0
\end{array}\right]\left[\begin{array}{c}
\hat{\vec{i}}_{s}^{s} \\
\hat{\vec{\lambda}}_{s}^{s}
\end{array}\right]+\left[\begin{array}{c}
\frac{1}{L_{\sigma}} \\
1
\end{array}\right] \vec{v}_{s}^{s}+G\left(\vec{i}_{s}^{s}-\hat{\vec{i}}_{s}^{s}\right),
$$

where "^" implies an estimated value, and $G$ is the observer gain matrix.

The proposed flux-observer-based speed estimation of an SFOC IM drive is shown in Fig. 1 , in which the speed error is obtained by subtracting the estimated rotor speed $\hat{\omega}_{r}$ from the rotor speed command $\omega_{r}^{*}$, this speed error is applied to the SFOC IM drive through a coordinate transformation of 2-axis synchronous to 3-phase stationary $\left(2^{e} \Rightarrow 3^{s}\right)$, and to trigger the voltage source inverter to run an IM. Furthermore, the current difference between the estimated stator current $\hat{\vec{i}}_{s}^{s}$ and the measured stator current $\vec{i}_{s}^{s}$ is acquired and modulated by the observer gain matrix $G$ to determine the estimated rotor speed $\hat{\omega}_{r}$, in which $\hat{\vec{i}}_{s}^{s}$ is derived from the stator flux estimator, and $\vec{i}_{s}^{s}$ is obtained from the IM by using Hall effect current sensors and coordinate transformation from 3 -phase stationary to 2-axis stationary $\left(2^{s} \Leftarrow 3^{s}\right)$.

\subsection{Lyapunov stability theory observer gain matrix design}

The gain matrix design of the proposed stator flux observer utilizes the Lyapuov stability theory. ${ }^{(15)}$ According to Eq. (6), the state equations of an IM at the stationary reference coordinate frame can be expressed as 


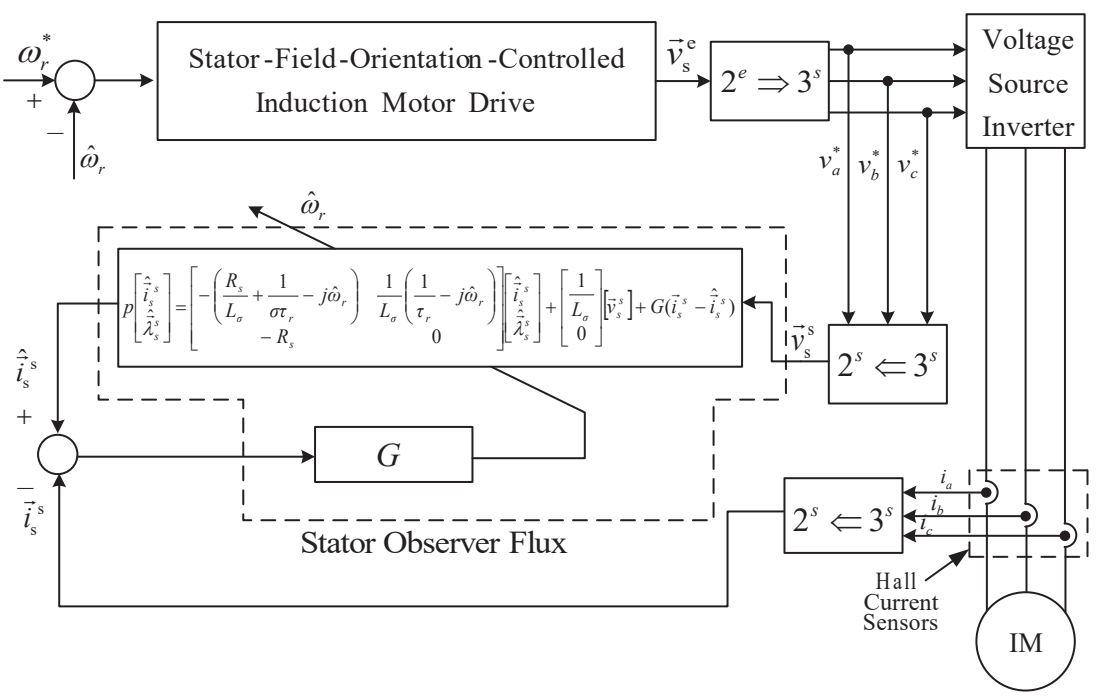

Fig. 1. Stator-flux-observer-based speed estimation of SFOC IM drive.

$$
\begin{gathered}
\dot{x}=\left[A+\omega_{r} A_{\omega}\right] x+B u, \\
y=C x,
\end{gathered}
$$

where $x=\left[\begin{array}{llll}i_{d s}^{s} & i_{q s}^{s} & \lambda_{d s}^{s} & \lambda_{q s}^{s}\end{array}\right]^{\mathrm{T}}, u=\left[\begin{array}{ll}v_{d s}^{s} & v_{q s}^{s}\end{array}\right]^{\mathrm{T}}, A=\left[\begin{array}{cc}-\left(\frac{R_{s}}{L_{\sigma}}+\frac{1}{\sigma \tau_{r}}\right) I & \frac{1}{L_{\sigma} \tau_{r}} I \\ -R_{s} I & O\end{array}\right], A_{\omega}=\left[\begin{array}{cc}J & -\frac{1}{L_{\sigma}} J \\ O & O\end{array}\right]$, $B=\left[\begin{array}{ll}\frac{1}{L_{\sigma}} I & I\end{array}\right]^{\mathrm{T}}, y=\left[\begin{array}{ll}i_{d s}^{s} & i_{q s}^{s}\end{array}\right]^{\mathrm{T}}, C=\left[\begin{array}{ll}I & O\end{array}\right], I=\left[\begin{array}{ll}1 & 0 \\ 0 & 1\end{array}\right], J=\left[\begin{array}{ll}0 & -1 \\ 1 & 0\end{array}\right]$, and $O=\left[\begin{array}{ll}0 & 0 \\ 0 & 0\end{array}\right]$. Moreover, in accordance with Eq. (17), the estimation state matrix is derived as

$$
\dot{\hat{x}}=\left[A+\hat{\omega}_{r} A_{\omega}\right] \hat{x}+B u+G(\hat{y}-y) .
$$

The estimation error is acquired by subtracting Eq. (19) from Eq. (17), giving

$$
\dot{e}=\left(A+\omega_{r} A_{\omega}-G C\right) e-\Delta \omega_{r} A_{\omega} \hat{x},
$$

where $e=x-\hat{x}$ and $\Delta \omega_{r}=\hat{\omega}_{r}-\omega_{r}$. Selecting the Lyapunov function as

$$
V\left(e, \Delta \omega_{r}\right)=e^{\mathrm{T}} H e+\frac{\left(\Delta \omega_{r}\right)^{2}}{\gamma_{\omega}},
$$

where $H$ is a symmetric positive definite matrix, the time derivative of the selected Lyapunov function can be derived as 


$$
\begin{aligned}
\dot{V}= & e^{\mathrm{T}}\left[(A-G C)^{\mathrm{T}} H+H(A-G C)+\omega_{r}\left(A_{\omega}^{\mathrm{T}} H+H A_{\omega}\right)\right] e \\
& -\Delta \omega_{r}\left[\hat{x}^{\mathrm{T}} A_{\omega}^{\mathrm{T}} H e+e^{\mathrm{T}} H A_{\omega} \hat{x}\right]+\frac{2\left(\Delta \omega_{r}\right)}{\gamma_{\omega}} \frac{d\left(\Delta \omega_{r}\right)}{d t},
\end{aligned}
$$

where $\gamma_{\omega}>0$ is a constant.

Set $\Delta \omega_{r}\left[\hat{x}^{\mathrm{T}} A_{\omega}^{\mathrm{T}} H e+e^{\mathrm{T}} H A_{\omega} \hat{x}\right]=2\left(\Delta \omega_{r}\right) / \gamma_{\omega} \cdot d\left(\Delta \omega_{r}\right) / d t$ in Eq. (22) and select $G$ and $H$ such that the inequality Eq. (23) is valid, and then the time derivative of the selected Lyapunov function is negative. According to the Lyapunov stability theory, Eq. (20) is asymptotically stable, and the established stator flux observer is also asymptotically stable.

$$
(A-G C)^{\mathrm{T}} H+H(A-G C)+\omega_{r}\left(A_{\omega}^{\mathrm{T}} H+H A_{\omega}\right)<0
$$

Select the adaptive law as

$$
\frac{d\left(\hat{\omega}_{r}\right)}{d t}=e^{\mathrm{T}} H A_{\omega} \hat{x}
$$

According to Eq. (24), the estimated rotor speed was derived as

$$
\hat{\omega}_{r}=K_{p o}\left[e^{\mathrm{T}} H A_{\omega} \hat{x}\right]+\frac{K_{i o}\left[e^{\mathrm{T}} H A_{\omega} \hat{x}\right]}{s},
$$

where $K_{p o}$ and $K_{i o}$ are adaptation gains.

\subsection{Observer gain matrix parameters with the PSO algorithm}

The PSO algorithm was used to acquire the observer gain matrix parameters in this study because it is very suitable for use in the presence of noise, time variance, and irregular conditions.

The PSO algorithm was devised to simulate social behavior, ${ }^{(16)}$ in which an iterative procedure is used to improve candidate solutions (called particles) to attain a prescribed degree of quality. The original conventional PSO algorithm has the disadvantage of local solution convergence, and modifications have been made such as in the constriction factors method, the dynamic system tracking method, and inertia weight method. ${ }^{(17)}$ The inertia weight method was used in this study because it promotes the search for an optimum solution in the initial computation stage and improves convergence quality in the follow-up computation. The inertia weight PSO algorithm applies the concept of progressive deceleration. In the inertia weight PSO algorithm, the particle is configured with large-scale fast search velocity in the initial stage, and when the iteration is gradually increased, the searching velocity is gradually decreased to improve convergence. The iteration formulas of the position, Eq. (26), and the velocity, Eq. (27), are 


$$
\begin{gathered}
V_{i}(k+1)=w \cdot V_{i}(k)+C_{1} \cdot \text { Rand } \cdot\left(P_{\text {best }}-x_{i}\right)+C_{2} \cdot \text { Rand } \cdot\left(G_{\text {best }}-x_{i}\right), \\
x_{i}(k+1)=x_{i}(k)+V_{i}(k+1),
\end{gathered}
$$

where $V_{i}(k)$ and $x_{i}(k)$ are the velocity and position of the particle, respectively, $P_{\text {best }}$ and $G_{\text {best }}$ are the optimum position solution of the individual particle and swarm particles, respectively, $w$ is the weighting factor, $C_{1}$ and $C_{2}$ are the learning factors, and Rand is the uniform distribution random variable over $\{0,1\}$.

On the right side of Eq. (26), the first item stands for the improvement effect of convergence, the second item stands for the cognition-only model of the particle, and the third item stands for the social-only model of the particles. The displacement and velocity of each particle are limited to the bounds between maximum and minimum. If the updated displacement and velocity of a particle exceed the bounds, then the updated values become the maximum and minimum. The two-dimensional search of velocity and position of the particles is shown in Fig. 2. The computation procedures of the inertia weight method PSO algorithm are shown in Fig. 3. These include allocating the initial position and velocity of the particle, the computation adaptation value, updating the optimal values of the individual particle and the swarm particles, and evaluation of the desired precision.

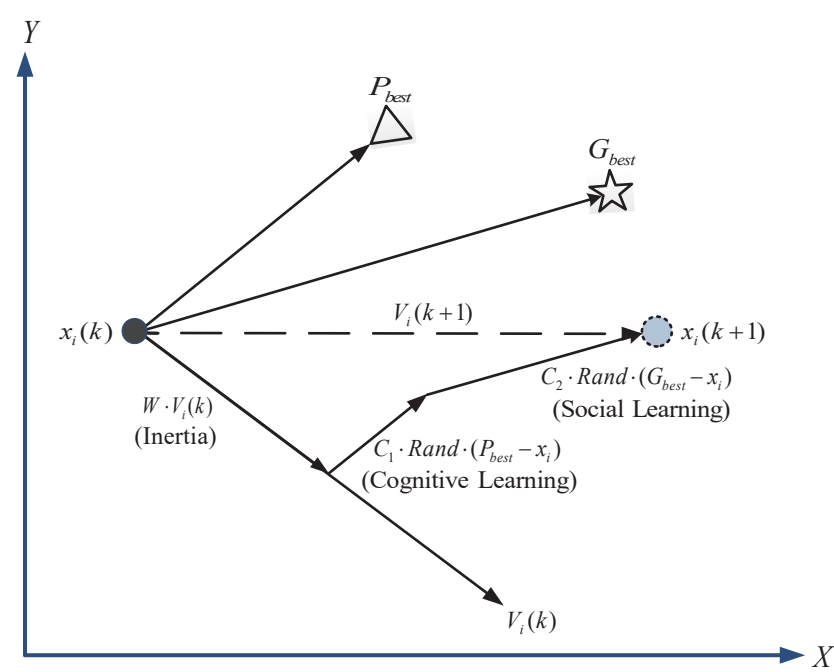

Fig. 2. (Color online) Two-dimensional search of velocity and position of particles.

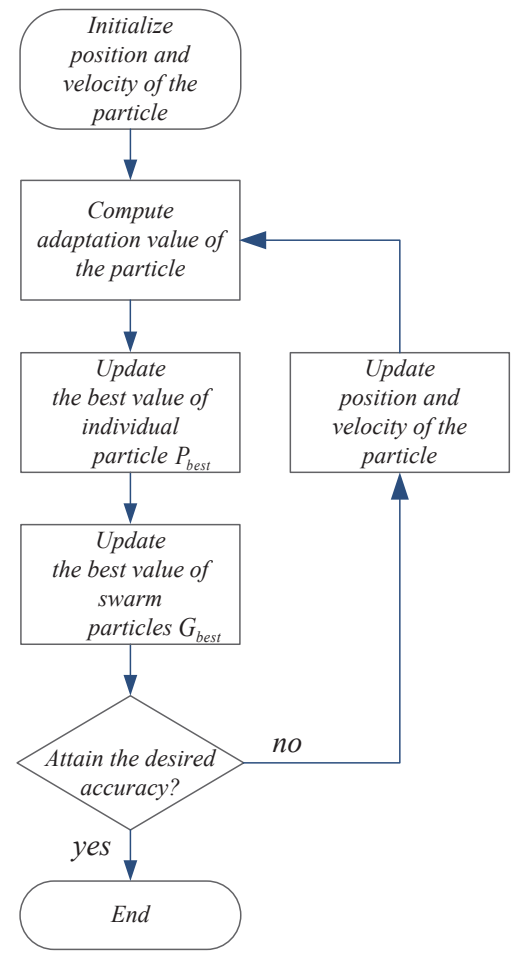

Fig. 3. (Color online) Computation flow of the inertia weight method PSO algorithm. 


\section{Simulation and Experiment}

A block diagram of the proposed speed estimation of SFOC IM drive based on the PSO algorithm stator flux observer is shown in Fig. 4. It includes stator-flux-observer-type speed estimation, slip speed calculation, flux controller, speed controller, $q$-axis and $d$-axis stator current controllers, flux command calculation, $q$-axis stator current command calculation, $d$-axis and $q$-axis stator voltage decoupling, and coordinate transformation. The stator current is obtained from the IM by using Hall effect current sensors for the implementation of this speed estimation of the SFOC IM drive.

In the proposed system, the proportion-integral (PI-type) controllers for the $d$-axis and $q$-axis stator current control loops, flux control loop, and speed control loop were designed by the root-locus method. The proportion gain $\left(K_{P}\right)$, integral gain $\left(K_{I}\right)$, and bandwidth (BW) for the four PI-type controllers are shown in Table 1, and the root locus and Bode plot of the designed flux controller are shown in Figs. 5 and 6, respectively.

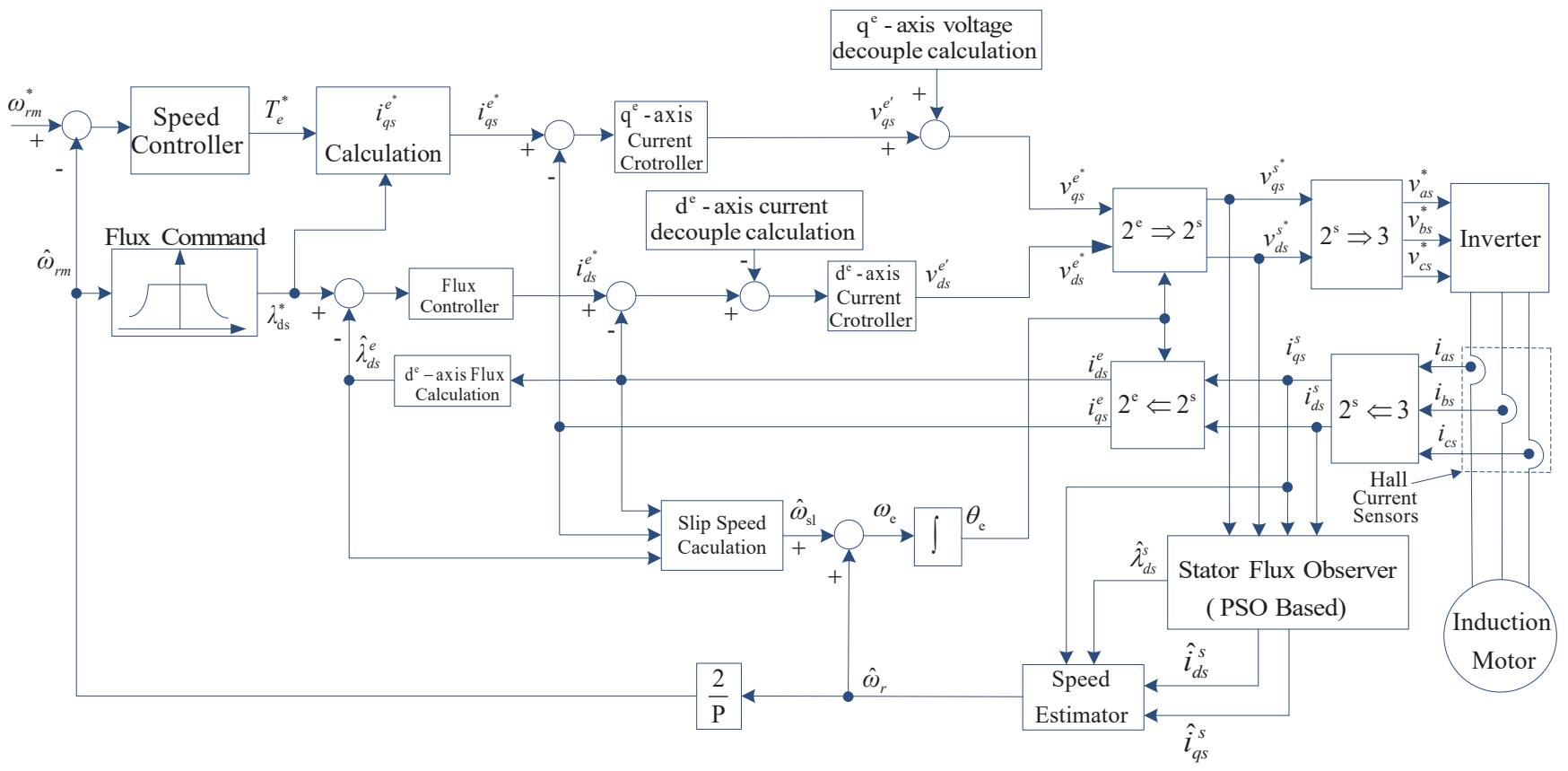

Fig. 4. (Color online) PSO algorithm stator-flux-observer-based speed estimation of SFOC IM drive.

Table 1

PI controller parameters and bandwidth.

\begin{tabular}{lrcc}
\hline & $K_{P}$ & \multicolumn{1}{c}{$K_{I}$} & $\mathrm{BW}(\mathrm{rad} / \mathrm{s})$ \\
\hline$d$-axis stator current controller & 20.41 & 2040.5 & 1930 \\
$q$-axis stator current controller & 4.37 & 655.6 & 1760 \\
Flux controller & 52.17 & 778.6 & 189 \\
Speed controller & 0.98 & 54.02 & 158 \\
\hline
\end{tabular}




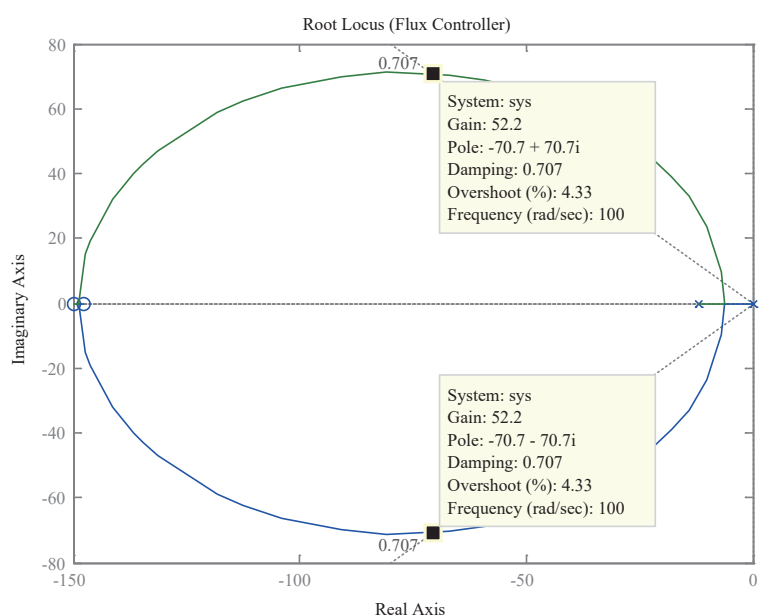

Fig. 5. (Color online) Root locus of the flux controller.

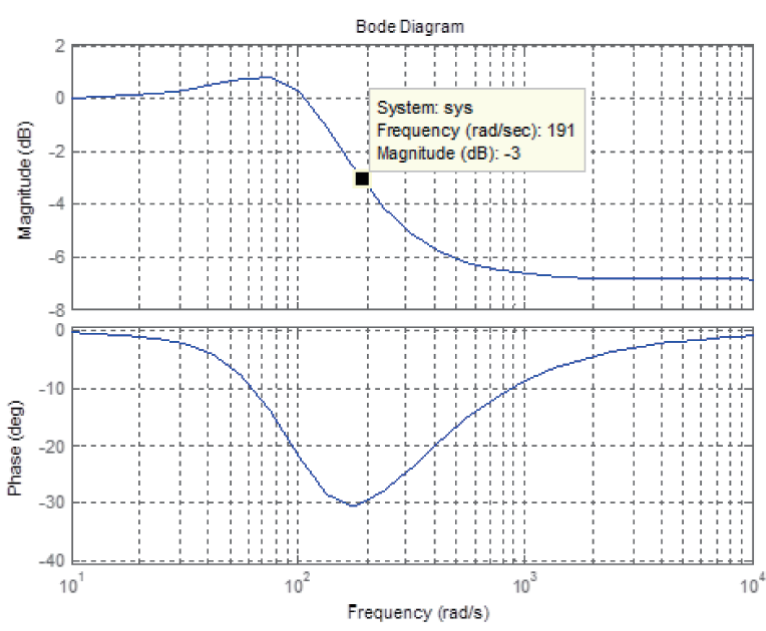

Fig. 6. (Color online) Bode plot of the flux controller.

A standard 3-phase, $220 \mathrm{~V}, 0.75 \mathrm{~kW}, \Delta$-connected, squirrel-cage IM (see Table 2 for motor parameters) was simulated, and a physical motor was used in experiments, to confirm the effectiveness of the proposed stator-flux-observer-based speed estimation of SFOC IM drive that used a PSO algorithm observer gain matrix design. The simulation was established using the MATLAB/Simulink toolbox, and all control algorithms were realized using the 32-bit micro controller RX62T to generate pulse width modulation (PWM) signals to the power stage and to run the motor in experimental validations. In a running cycle, the symmetrical speed commands used were as follows: forward direction acceleration from $t=0$ to $t=1 \mathrm{~s}$, forward direction steady-state operation during $1 \leq t \leq 2 \mathrm{~s}$, forward direction braking operation to reach zero speed in the interval $2 \leq t \leq 3 \mathrm{~s}$, reverse direction acceleration from $t=3$ to $t=4 \mathrm{~s}$, reverse direction steady-state operation during $4 \leq t \leq 5 \mathrm{~s}$, and reverse direction braking operation to reach zero speed in the interval $5 \leq t \leq 6 \mathrm{~s}$.

The simulated and measured responses of the first two running cycles are shown in Figs. 7-12. Each figure contains four responses: the estimated shaft speed and actual shaft speed, the stator current, the electromagnetic torque, and the stator flux locus. The simulated and measured responses with a $2 \mathrm{~N} \cdot \mathrm{m}$ load for reversible speed commands of $\pm 1800, \pm 900$, and \pm 300 rpm are shown in Figs. 7 and 8, Figs. 9 and 10, and Figs. 11 and 12, respectively.

An accurate estimate of shaft speed was obtained under load conditions in the simulations and experiments at different operational speeds as shown in Figs. 7-12. Excellent responses of both stator current and electromagnetic torque were obtained and the proper coordinate transformation was achieved and verified with the circular shape of the stator flux locus, showing that the desired performance can be attained in the proposed system. 
Table 2

IM parameters.

\begin{tabular}{lc}
\hline Poles & 4 \\
$R_{S}$ & $2.85 \Omega$ \\
$R_{r}$ & $2.3433 \Omega$ \\
$L_{s}$ & $0.1967 \mathrm{H}$ \\
$L_{r}$ & $0.1967 \mathrm{H}$ \\
$L_{m}$ & $0.1886 \mathrm{H}$ \\
$J_{m}$ & $0.009 \mathrm{Nt}-\mathrm{s}^{2} / \mathrm{m}$ \\
$B_{m}$ & $0.00825 \mathrm{Nt}-\mathrm{s} / \mathrm{m}$ \\
\hline
\end{tabular}

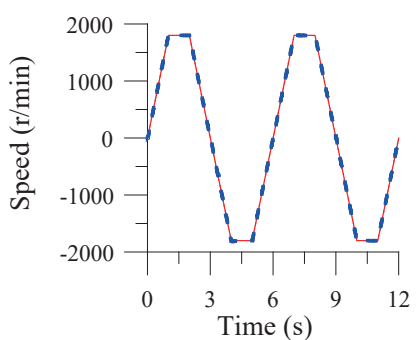

(a)

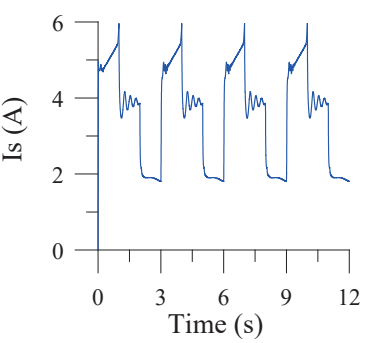

(b)

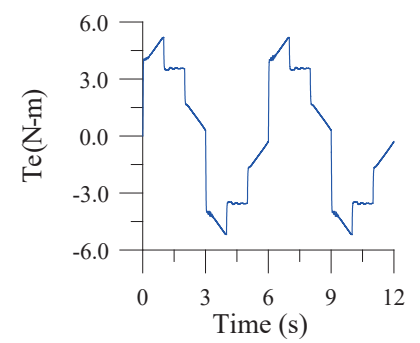

(c)

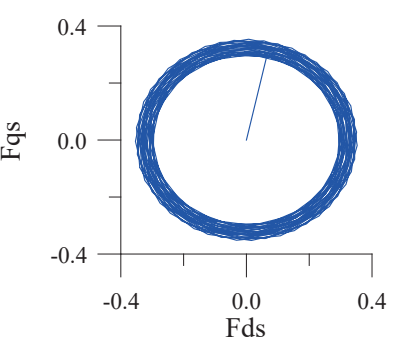

(d)

Fig. 7. (Color online) Simulated responses of the PSO algorithm flux observer design speed estimation of SFOC IM drive with a $2 \mathrm{~N} \cdot \mathrm{m}$ load at the reversible steady-state speed command of $\pm 1800 \mathrm{rpm}$. (a) Command (solid line) and estimated (dotted line) rotor-shaft speed, (b) stator current, (c) estimated electromagnetic torque, and (d) stator flux locus ( $q$-axis vs $d$-axis).

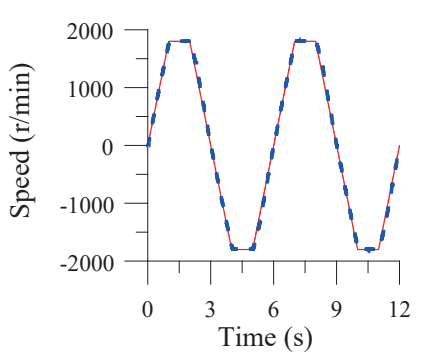

(a)

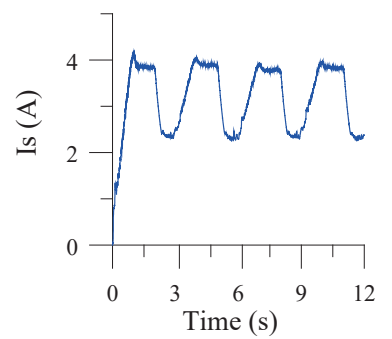

(b)

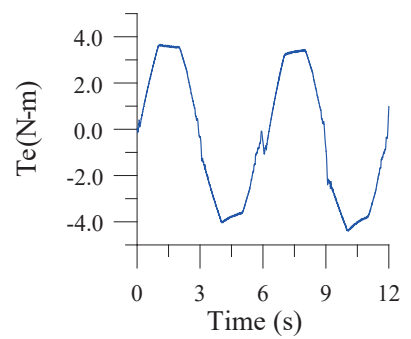

(c)

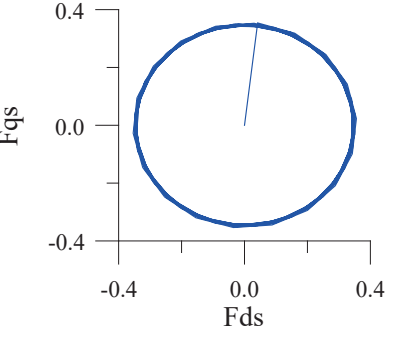

(d)

Fig. 8. (Color online) Measured responses of the PSO algorithm flux observer design speed estimation of SFOC IM drive with a $2 \mathrm{~N} \cdot \mathrm{m}$ load at the reversible steady-state speed command of $\pm 1800 \mathrm{rpm}$. (a) Command (solid line) and estimated (dotted line) rotor-shaft speed, (b) stator current, (c) estimated electromagnetic torque, and (d) stator flux locus ( $q$-axis vs $d$-axis).

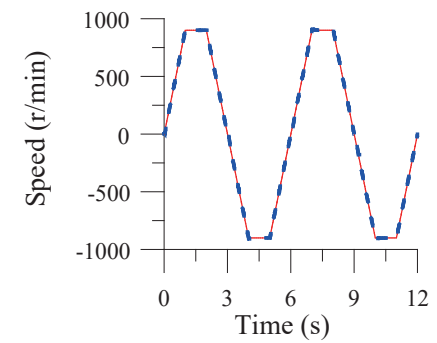

(a)

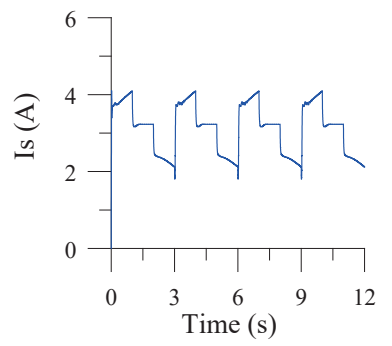

(b)

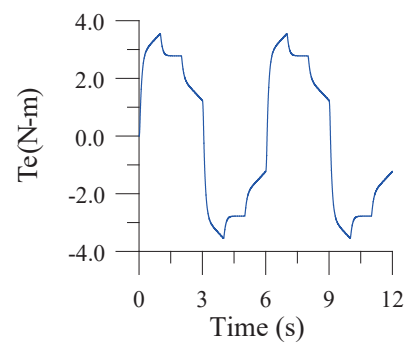

(c)

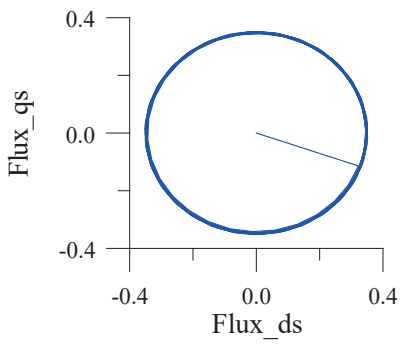

(d)

Fig. 9. (Color online) Simulated responses of the PSO algorithm flux observer design speed estimation of SFOC IM drive with a $2 \mathrm{~N} \cdot \mathrm{m}$ load at the reversible steady-state speed command of $\pm 900 \mathrm{rpm}$. (a) Command (solid line) and estimated (dotted line) rotor-shaft speed, (b) stator current, (c) estimated electromagnetic torque, and (d) stator flux locus ( $q$-axis vs $d$-axis). 


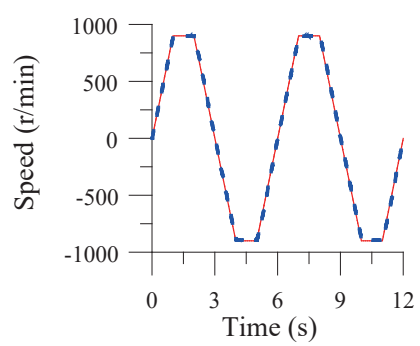

(a)

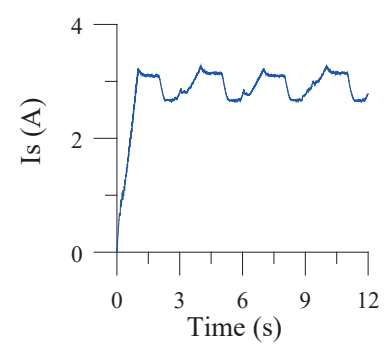

(b)

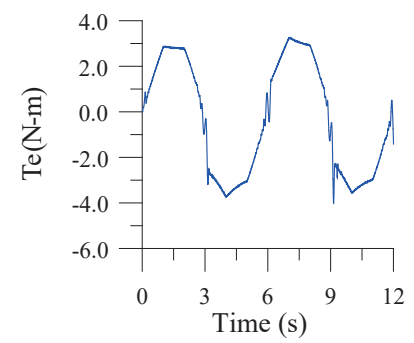

(c)

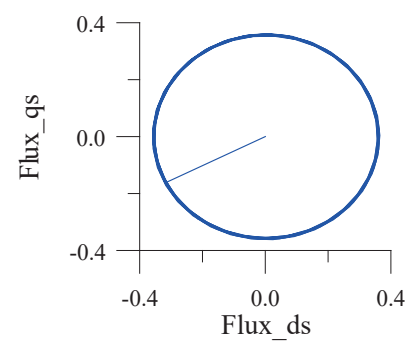

(d)

Fig. 10. (Color online) Measured responses of the PSO algorithm flux observer design speed estimation of SFOC IM drive with a $2 \mathrm{~N} \cdot \mathrm{m}$ load at the reversible steady-state speed command of $\pm 900 \mathrm{rpm}$. (a) Command (solid line) and estimated (dotted line) rotor-shaft speed, (b) stator current, (c) estimated electromagnetic torque, and (d) stator flux locus ( $q$-axis vs $d$-axis).

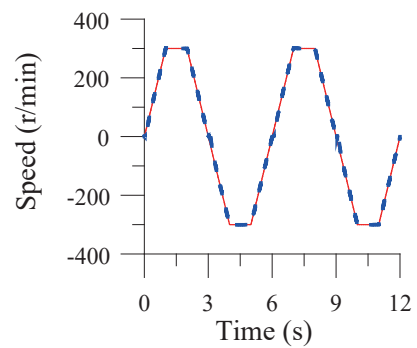

(a)

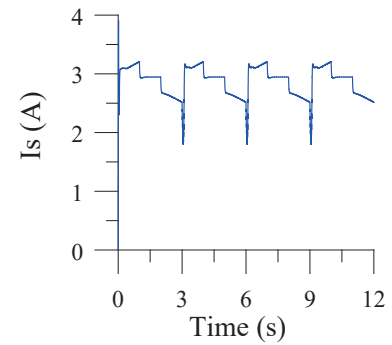

(b)

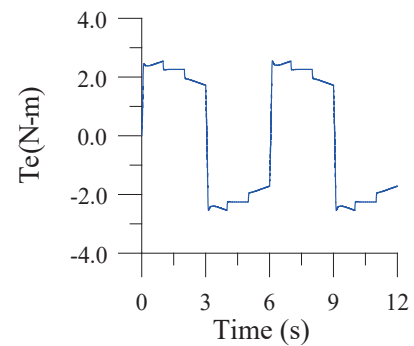

(c)

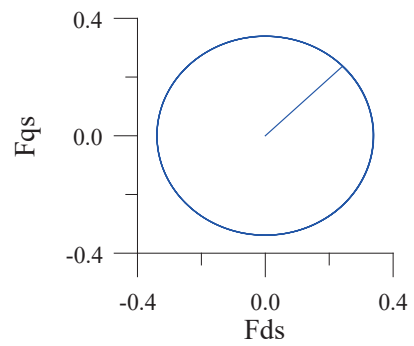

(d)

Fig. 11. (Color online) Simulated responses of the PSO algorithm flux observer design speed estimation of SFOC IM drive with a $2 \mathrm{~N} \cdot \mathrm{m}$ load at the reversible steady-state speed command of $\pm 300 \mathrm{rpm}$. (a) Command (solid line) and estimated (dotted line) rotor-shaft speed, (b) stator current, (c) estimated electromagnetic torque, and (d) stator flux locus ( $q$-axis vs $d$-axis).

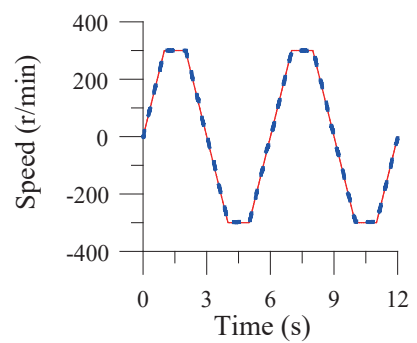

(a)

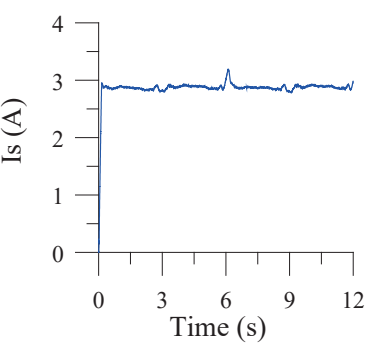

(b)

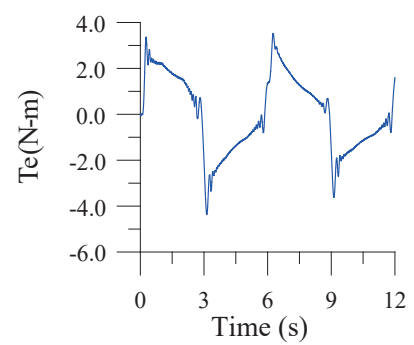

(c)

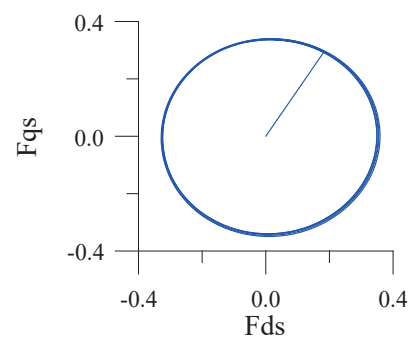

(d)

Fig. 12. (Color online) Measured responses of the PSO algorithm flux observer design speed estimation of SFOC IM drive with a $2 \mathrm{~N} \cdot \mathrm{m}$ load at the reversible steady-state speed command of $\pm 300 \mathrm{rpm}$. (a) Command (solid line) and estimated (dotted line) rotor-shaft speed, (b) stator current, (c) estimated electromagnetic torque, and (d) stator flux locus ( $q$-axis vs $d$-axis).

\section{Conclusion}

A stator flux observer rotor-shaft speed on-line estimation by the PSO algorithm observer gain matrix design strategy has been proposed to control an SFOC IM drive. The proposed speed estimation scheme using the stator flux observer has the advantage of both simple structure and implementation. The flux observer gain matrix uses a PSO algorithm, which can rapidly acquire the exact gain parameters. The stator current measurement, isolation, and protection are provided by the Hall effect current sensors for this speed estimation of SFOC 
IM drive. The simulation and experimental responses at different reversible steady-state speed commands $( \pm 1800, \pm 900$, and $\pm 300 \mathrm{rpm})$ confirm the effectiveness of the proposed approach. The flux observer gain matrix design use of a fuzzy logic control strategy is the future research direction.

\section{References}

Y. C. Luo and W. X. Chen: CMA 64 (2012) 1206.

M. Zaky: IEEE Trans. Ind. Electron. 59 (2012) 858.

G. D. Marques, D. M. Sousa, and M. F. Iacchetti: IEEE Trans. Energy Convers. 28 (2013) 959.

4 G. D. Marques and D. M. Sousa: IEEE Trans. Ind. Electron. 58 (2011) 4717.

5 A. S. Morsy, A. S. A. Khalik, S. Ahmed, and A. Massoud: Proc. IEEE ECCE (2013) 5112.

6 R. Kumar, S. Das, and A. K. Chattopadhyay: Proc. MFIET (2015) 319.

7 M. Comanescu and P. S. Altoona: Proc. IEEE SCED (2017) 213.

8 W. Pawlus, S. T. Kandukuri, G. Hovland, M. Choux, and M. R. Hansen: Proc. IEEE ICIT (2016) 153.

9 Y. Wenqiang, C. Xu, and J. Jianguo: Proc. IEEE PEDS (2003) 423.

10 M. N. Uddin, Z. R. Huang, and A. B. M. Siddique Hossain: IEEE Trans. Ind. Appl. 50 (2014) 51.

11 M. Caruso, V. Cecconi, A. O. D. Tommaso, and R. Rocha: Proc. EM (2012) 1062.

12 R. P. Vieira, T. S. Gabbi, and H. Gründling: Proc. IEEE IES (2014) 844.

13 Y. C. Luo, Z. S. Ke, and Y. P. Kuo: MPE. ID 861462 (2014), 13.

14 C. H. Liu: Control of AC Electrical Machines (Tunghua, Taipei, 2008) (in Chinese).

15 B. Shafai: System Identification and Adaptive Control (Springer Verlag, 2014).

16 L. D. S. Coelho, L. Z. Barbosa, and L. Lebensztajn: IEEE Trans. Mag. 46 (2010) 2994.

17 M. Hinkkanen: IEEE Trans. Ind. Electron. 51 (2004) 1033.

\section{About the Authors}

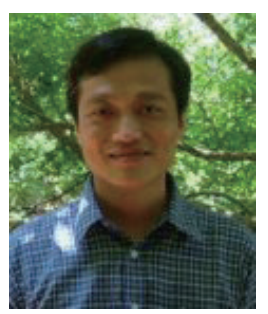

Yung-Chang Luo received his M.S. and Ph.D. degrees from National Taiwan University of Science and Technology, Taipei, Taiwan, ROC, in 1991 and 2000, respectively. He is currently an associate professor in the Department of Electrical Engineering, National Chin Yi University of Technology, Taichung, Taiwan, ROC. His current research interests include speed estimation of ac motor drives, front-end power factor correction of converter, and the design of micro controller based motor drive.

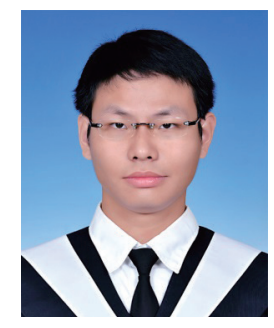

Chen-Lung Tsai was born in March 1992. He received his Master's degree in electrical engineering from National Chin-Yi University of Technology, Taiwan, in July 2016. His main research focus is on speed estimation of FOC IM drives.

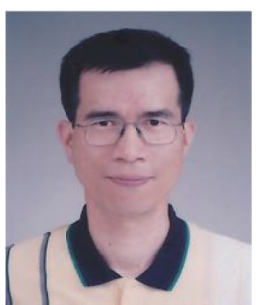

Ying-Piao Kuo received his B.S. degree in electrical engineering in 1985 from National Taiwan University of Science and Technology, Taipei, Taiwan, M.S. degree in electrical engineering in 1989 from National Taiwan University, and Ph.D. degree from National Taiwan University of Science and Technology, Taipei, Taiwan, in 2011. In 1989, he joined National Chin-Yi University of Technology, Taichung, Taiwan, where he is currently an associate professor in the Department of Electrical Engineering. His current research interests include design of switching-mode power supplies, partial discharge, and power system stability. 